\title{
SIMULATION OF REAL DRIVING CYCLES OF ELECTRIC CARS IN LABORATORY CONDITIONS
}

This article is focused on the area of research and development of vehicles with electric drive. The paper presents the results of research based on real electric vehicle EDISON EV as the real traffic in laboratory conditions reflecting. The analysis of special driving style was created in order to increase electric vehicle range.

Keywords: Simulation, driving cycle, electric vehicle, roller dynamometer.

\section{Single roller dynamometer MAHA MSR 1050 -equipment for driving simulation}

MAHA MSR 1050 is a premium model of single roller dynamometer for cars (SRD). It is equipped with precise axle regulation. The maximum test speed is $320 \mathrm{~km} / \mathrm{h}$ and maximum power to the front / rear axle $1000 / 2000 \mathrm{~kW}$. We are able to measure vehicles, which are all- wheel drive, including long- term endurance tests of high-performance vehicles without damaging of the tires because each wheel is placed on a separate roller. The position of the vehicle is higher than the "2 roller" and that is a guarantee of better airflow under the vehicle. The SRD is equipped with an electric drive of roller, which extends the capabilities of

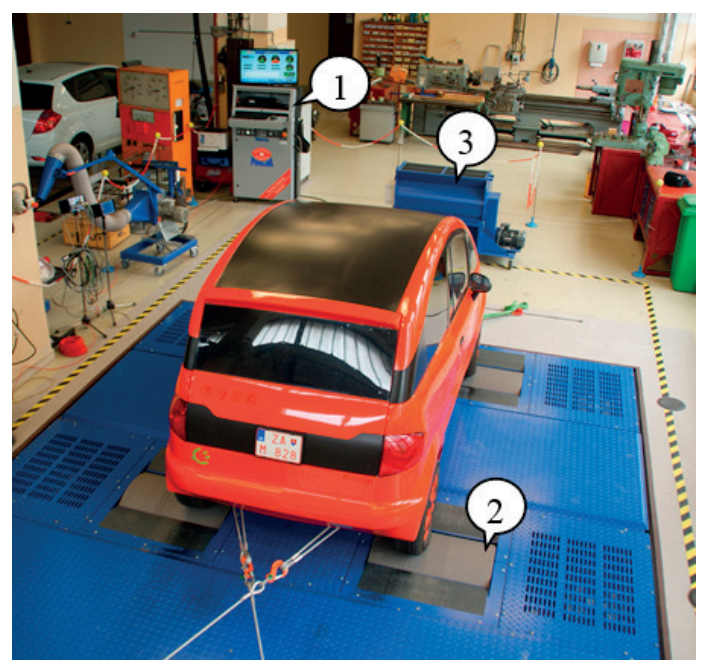

Fig. 1 MAHA MSR 1050 and EV Edison conducting tests significantly. The active rollers allow testing of an electric vehicle or a vehicle with a hybrid drive [1]. In Fig. 1 is shown SRD MAHA MSR 1050 with: 1 - Communication counter with PC, 2 - Rollers, 3 - Cooling ventilator.

It is possible to do precise simulation of defined types of traffic for processing of different measurement tasks. Basic operation modes are measuring of performance and simulation of engine load. The simulation allows the user to load a preset of various loading conditions, for example: constant pulling force, constant speed, constant rpm and driving simulation. The driving simulation is a simulation where the wind force is not applied. We need to know and enter the index of individual driving resistances and the mass of the vehicle. The driving simulation is performed by programming a driving mode and a braking mode [2 - 3].

\section{The simulation of electromobile with using driving cycles}

Specific measurement in the mode of driving simulation is a driving cycle. The driving cycles are used as an input parameter to the simulation of a vehicle driving for assessing the energy consumption because energy is transformed into traction purposes. The driving cycle is defined as dependence of speed and time. This driving cycle is repeatable and analyzes energy balance of electric vehicle (EV) [4]. New European Driving Cycle (NEDC) is a driving cycle, which is designed to assess the level of engine emissions and consumption of traction energy for a passenger car. New European Driving Cycle (NEDC) is a compilation of the urban and out of city simulation because of

\footnotetext{
* Lubos Kucera, Tomas Gajdosik, Igor Gajdac, Martin Mruzek, Maria Tomasikova

Department of Design and Mechanical Elements, Faculty of Mechanical Engineering, University of Zilina, Slovakia

E-mail: lubos.kucera@fstroj.uniza.sk
} 


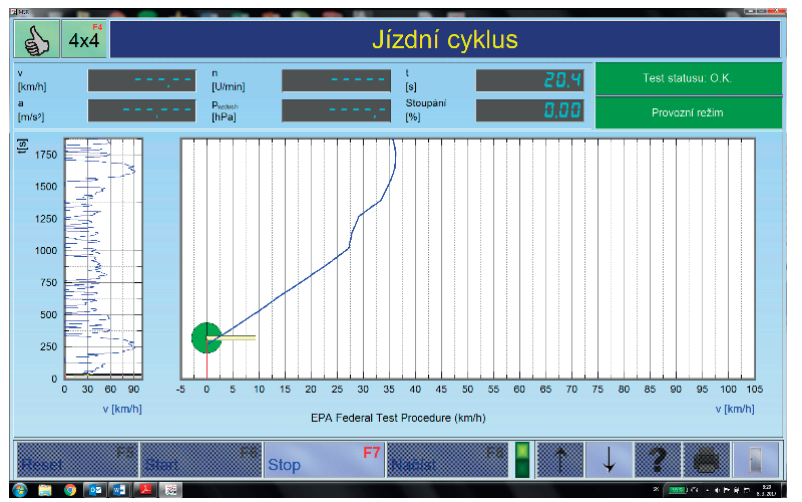

Fig. 2 Driving cycle

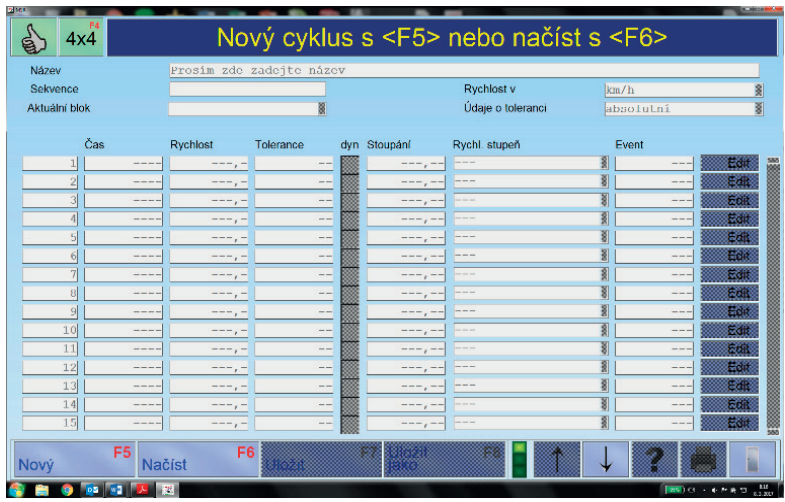

Fig. 3 Creation of new driving cycle

the effort of being as close to reality as possible. NECD consists of 2 parts. The first one is UDC (Urban Driving Cycle) which consists of 4 cycles while one of them takes 195 seconds. The second part is EUDC (Extra Urban Driving cycle) with top speed - $120 \mathrm{~km} / \mathrm{h}$. NEDC will be replaced by WLTP cycle (Worldwide harmonized Light vehicles Test Procedure), which would be more relevant to real conditions [5].

It is possible to observe the speed profile with established time and speed courses during the test of a driving cycle. Required course of the curve is displayed (Fig. 2) on the screen for a test driver.

Software database contains different standard driving cycles and it is possible to create your own driving cycle using the editor (Fig. 3).

We monitor consumption of electric energy of an electric vehicle by a wide range of MAHA settings, precisely this allows us to optimize individual indicators. The most important negative indicator is mass in terms of design variables. The mass may

be influenced during the design. Operational indicators may be influenced by the driver. If intelligent traffic management helps the driver with optimal routes or the driver must deal with the impact of climatic conditions and the environmental conditions in which the electric vehicle is driving. The direct impact of the driver on the range of the vehicle is a driving style in form of minimizing braking and accelerating, smooth driving and the use of recovery and coasting. These actions are the most demanding in terms of energy [6].

The advantage of the Edison Electric Car is the possibility of programming various control system parameters such as the throttle response or intensity of recovery. Edison also makes possible the logging of important operation data from converter and BMS (battery management system). This data is used for evaluation of energy consumption and driving range. You can also observe courses of current, voltage drop or temperature of various components during the driving cycle. In Fig. 4 is shown the course of performance during urban driving cycle of NEDC [7].

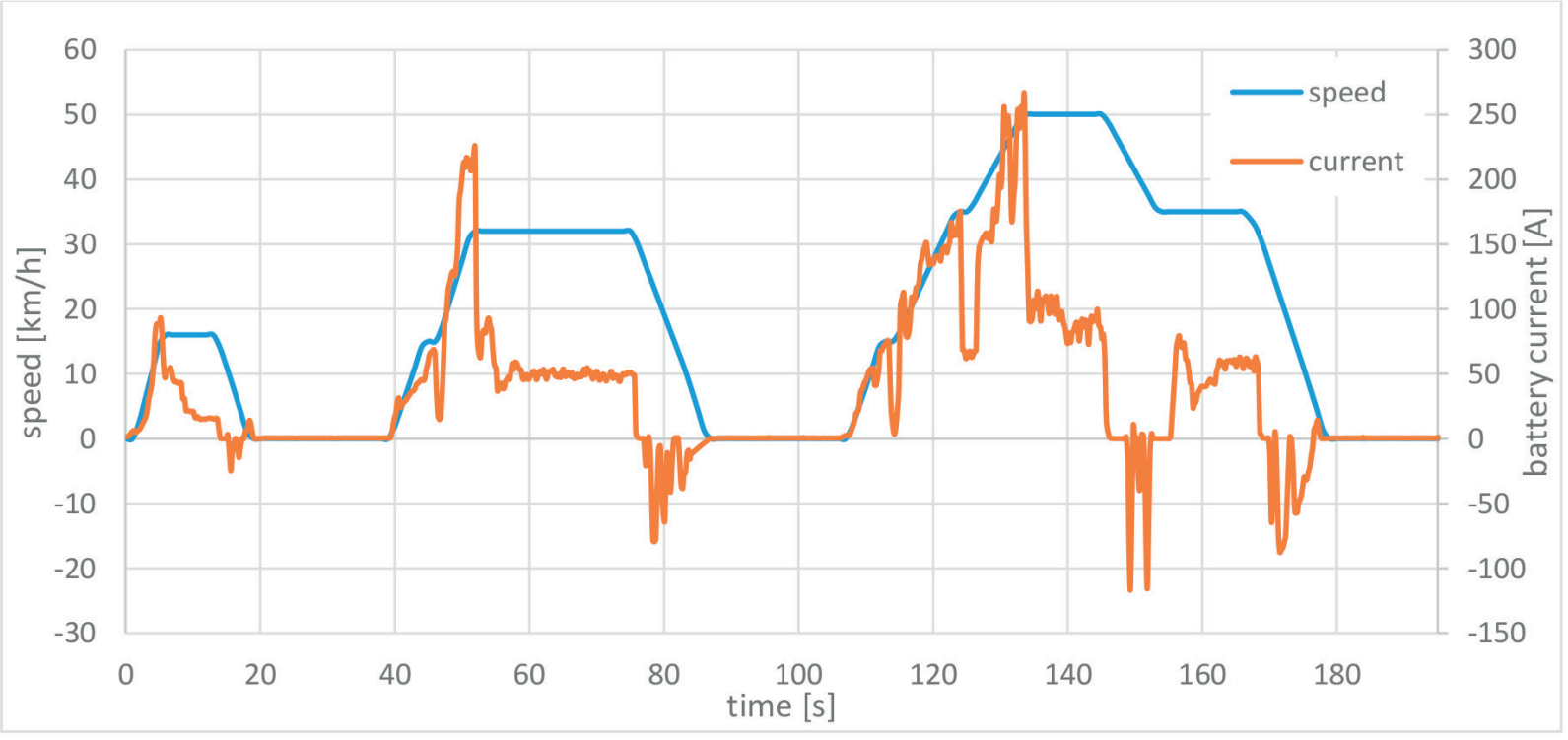

Fig. 4 Performance of urban driving cycle 


\section{Driving resistances}

It is necessary to know the driving resistance for vehicle simulation according to the driving cycle. The driving resistances and the total mass of the vehicle have to be taken into account in the driving simulation by SRD. Values of rolling resistance can be obtained from coast down tests. In Fig. 5 is shown a curve of the rolling resistance, which is obtained under the speed of deceleration of the vehicle during coast down tests. Equation 1 is polynomial, which describes this curve.

$F=0.38 v^{2}+6.58 v+126$

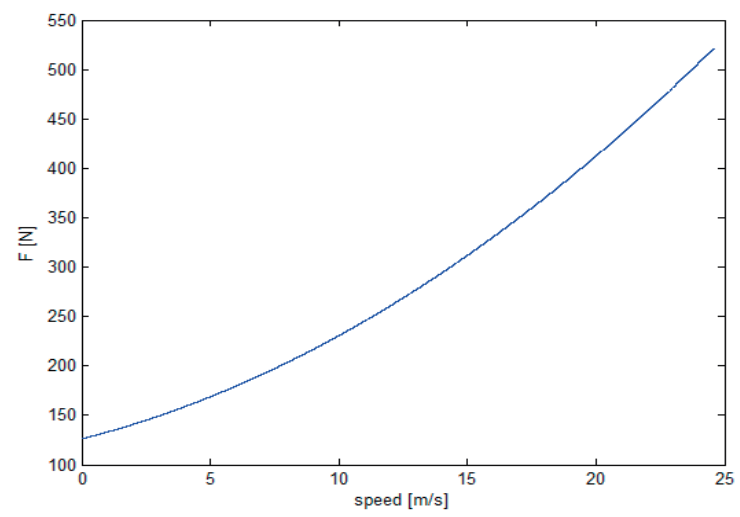

Fig. 5 Curve of driving resistances

Driving resistances are represented by individual coefficients. The correct values of the coefficients are the most important data for the simulation of driving cycles. The coefficients have to be set using the program as is shown in Fig. 6 [8].

Coefficient A $[\mathrm{kW}]$ - required power to overcome rolling resistance

$A=f \cdot m \cdot g \cdot v_{\text {ref }}$

$\mathrm{f}$ - coefficient of rolling resistance

$\mathrm{m}$ - vehicle mass $[\mathrm{kg}]$

g - gravitational acceleration $9.81\left[\mathrm{~m} / \mathrm{s}^{2}\right]$

$\mathrm{V}_{\text {ref }}$ - reference speed $25[\mathrm{~m} / \mathrm{s}](90 \mathrm{~km} / \mathrm{h})$

Coefficient B $[\mathbf{k W}]$ - rolling resistance performance which expresses distortion on roll the measuring device. It is included in A coefficient for practice.

Coefficient $\mathbf{C}[\mathrm{kW}]$ - power to overcome air resistance

$$
C=0.5 \cdot \rho \cdot C_{x} \cdot S_{x} \cdot v_{r e f}^{3}
$$

$\rho$ - air density $1.29\left[\mathrm{~kg} / \mathrm{m}^{3}\right]$

$\mathrm{C}_{\mathrm{x}}$ - drag coefficient

$\mathrm{S}_{\mathrm{x}}$ - frontal area of vehicle $\left[\mathrm{m}^{2}\right]$

$\mathrm{V}_{\text {ref }}$ - reference speed $25[\mathrm{~m} / \mathrm{s}](90 \mathrm{~km} / \mathrm{h})$

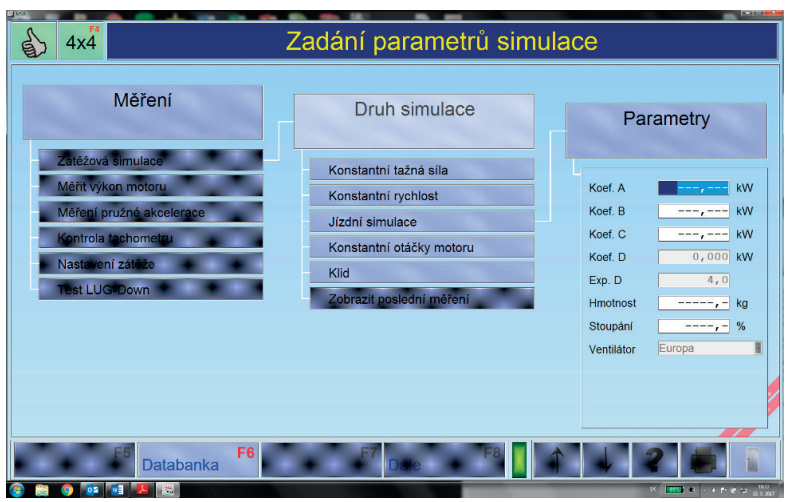

Fig. 6 Coefficient of driving resistance

Comparison of the coefficients of standard vehicles and experimental electric vehicle Edison is shown in Table 1 [9].

Comparison of coefficients of standard vehicles and electric vehicle Edison

Table 1

\begin{tabular}{|l|c|c|}
\hline \multicolumn{1}{|c|}{ Vehicle } & Coefficient A [kW] & Coefficient $\mathbf{C}[\mathbf{k W}]$ \\
\hline Mitsubishi i-Miev & 3.9 & 8.2 \\
\hline Nissan Leaf II & 5.1 & 6.8 \\
\hline Edison & 4.4 & 8.1 \\
\hline
\end{tabular}

The verification of the calculated coefficients can be based on the results of measurement of the coast down test or it can be based on measurement of coast down test on MAHA. When the value of power is at the maximum then the e-pedal is released this is the deceleration phase, which is expressed by the curve of power loss (loss of mechanical drive components, loss of tires) [10].

\section{The simulation and testing of vehicle by MAHA}

Range anxiety is a major obstacle for the development of electric cars. This is the reason why the research of electromobility is focused on the increase of driving range. One approach to

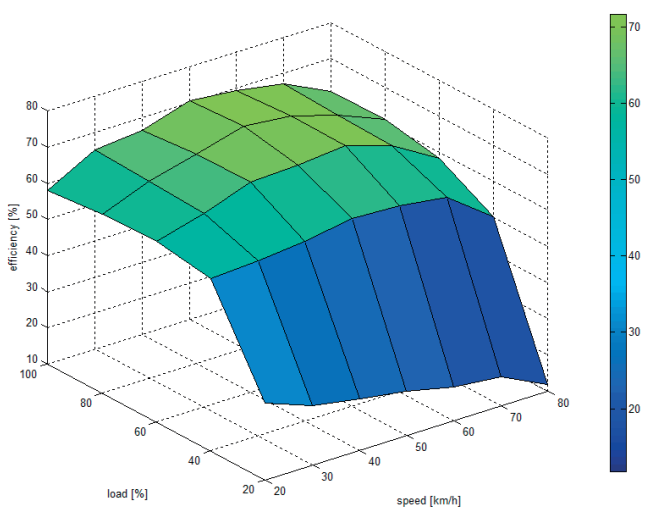

Fig. 7 Efficiency map of drive 
extend the range is the optimization of the driving style. In order to know more about the efficiency it is good to map the drive efficiency. This can be visualized thanks to Edison and MAHA MSR 1050 datalogging. Figure 7 shows the efficiency map of the drive, which is based on measurements of Edison.

Efficiency map shows that the vehicle drive for a steady ride is an area with lower efficiency. Edison Electric Car has one step planetary gearbox like the most of electric cars. That is the reason why it is not possible to move within the efficiency map in an area with a higher load as well as higher efficiency. The gear ratio of gearbox is designed to ensure dynamic parameters of the vehicle.

We can increase efficiency of Edison by creating a special driving style. The advantage of an electric vehicle is that it allows to recuperate kinetic energy during braking. This is great in urban traffic. On the other hand, the most efficient option is using coasting. Based on analysis and measurement of run-up it was found out that at higher accelerations the power consumption is the same as at low accelerations. This resulted into the creation of

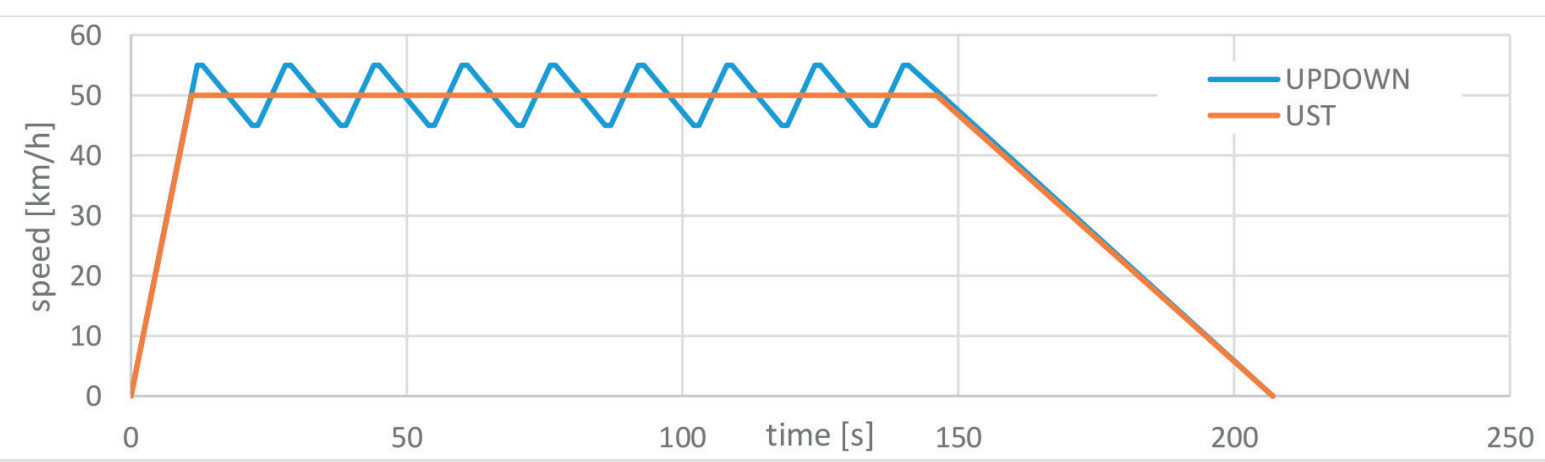

Fig. 8 Driving cycles: continual speed - orange, Up-down speed - blue

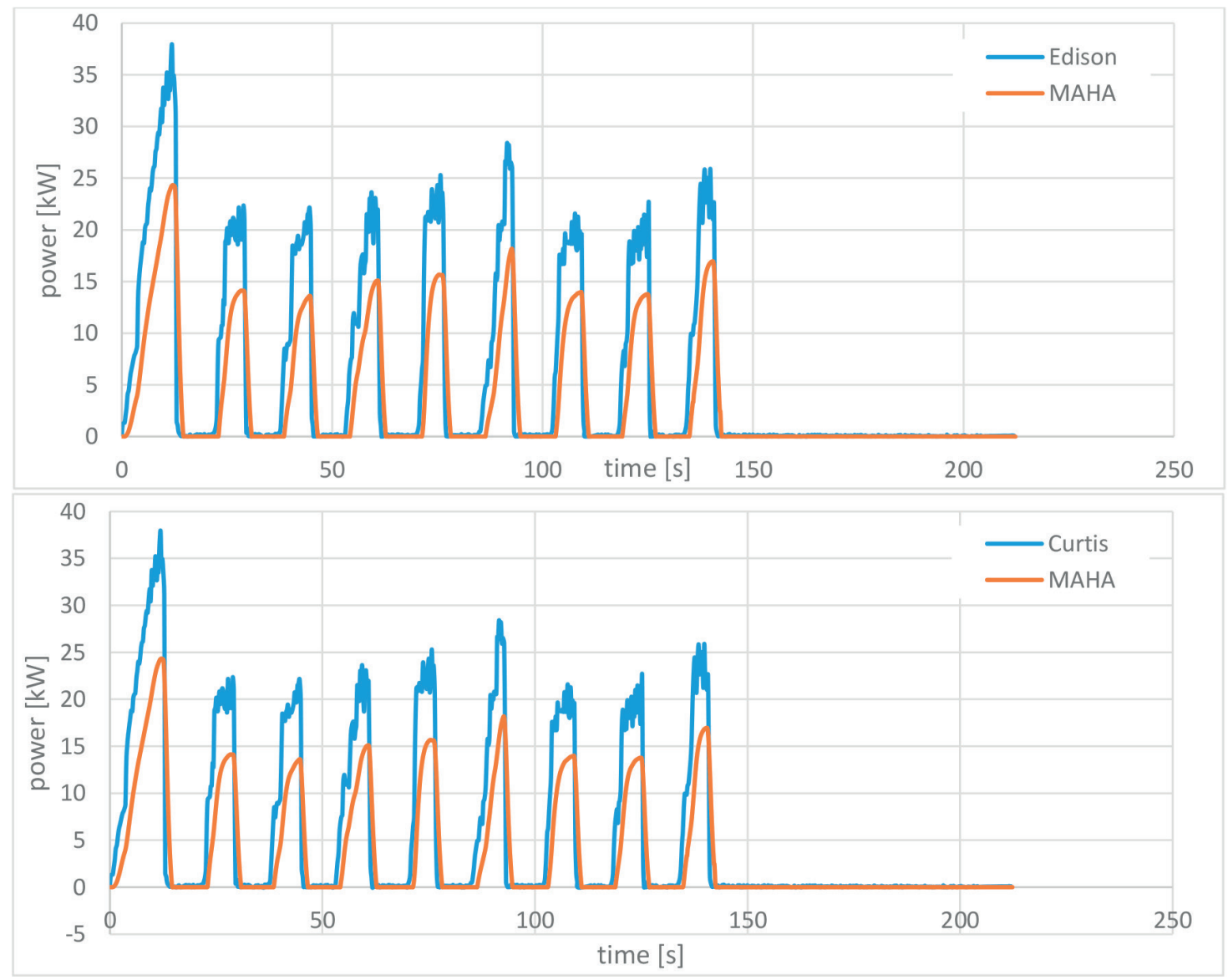

Fig. 9 Energy balance: Battery power - blue, SRD (MAHA) power - orange 
an experimental driving style UP-DOWN cycle. This UP-DOWN cycle is shown in Fig. 8 .

This driving style assumes the longer time of energy-efficiency for the free wheel will compensate for higher acceleration. Driving style is created for city traffic where the speed is mostly $50 \mathrm{~km} / \mathrm{h}$. The UP-DOWN cycle uses acceleration from $45 \mathrm{~km} / \mathrm{h}$ to $55 \mathrm{~km} / \mathrm{h}$ and follows a free wheel regime from $55 \mathrm{~km} / \mathrm{h}$ to $45 \mathrm{~km} / \mathrm{h}$. This is different between the steady ride and driving style. The drive will work with higher efficiency during UP-DOWN cycle. It has to overcome higher driving resistances. The energy consumption will be zero if it is a free wheel. This is an advantage of electric vehicles against the conventionally powered vehicles with internal combustion engine - if such a car idles, its energy consumption is not zero.

In Fig. 8 is a comparison of the driving cycle UP-DOWN with steady ride cycle. Distance and time are the same in both cycles. The distance is $2.4 \mathrm{~km}$.

Energy consumption of the battery is $0.33 \mathrm{kWh}$ for UP-DOWN driving cycle also for steady ride cycle. Situation is different in term of energy, which is measured on tires. The UP-DOWN cycle is more energy intensive than steady ride and this is confirmed by measurements. The average required energy for passing UP-DOWN cycle is $0.21 \mathrm{kWh}$, while for steady speed required energy is $0.17 \mathrm{kWh}$. In Fig. 9 is shown a course of tire power requirement and course of battery power requirement. It shows that the vehicle needs more energy for overcoming rolling resistance during UP-DOWN cycle. Total energy consumption is equal for both driving cycles.

The efficiency of powertrain is $62 \%$ for UP-DOWN cycle. That is more than $10 \%$ compared to steady ride cycle. Consumed energy from the battery is identical in both cases. Thus, the usage of UP-DOWN driving style is not useful in normal traffic because it does not extend the driving range.

\section{The other utilization of measured data from SRD}

It is possible to obtain a lot of information from measurements by SRD. We can use this data and information for many different simulations. One of them can be a simulation by Simscape Driveline.

We created a vehicle model in this software and we used measured data as input data. The data can be implemented into the simulation environment by using Simscape block -Look- Up Table. We are able to create an engine torque map from the measured data. Then the engine map looks like it is shown in Fig. 10. In Fig. 11 is shown a subsystem which represents the electric motor.4

The engine subsystem is made by blocks- Look Up Table, Gain, Integrator. Mathematical expression of this subsystem is

$M=I \cdot \alpha=I \cdot \frac{d w}{d t}$ where: M- torque; I - Inertia; $\alpha$ - angular acceleration; $\omega$ - angular velocity; $\mathrm{t}$ - time. This subsystem is further used as the engine for simulation of vehicle- electric vehicle. Input data are measured. That is why this model of engine is realistic.

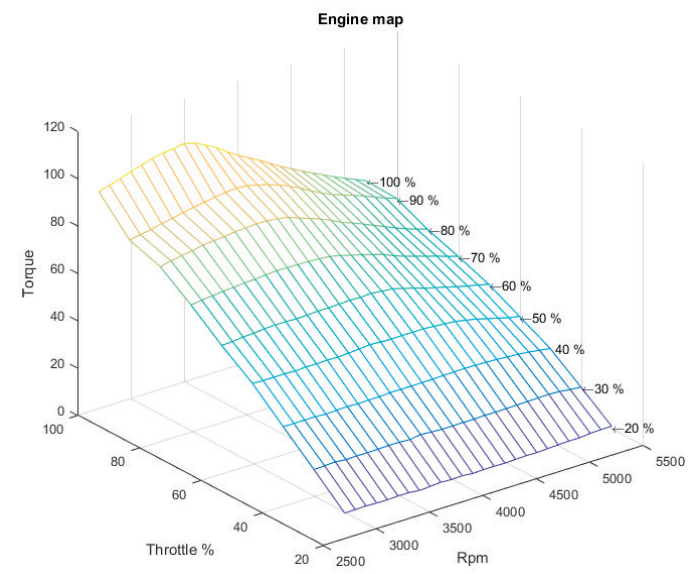

Fig. 10 Engine map

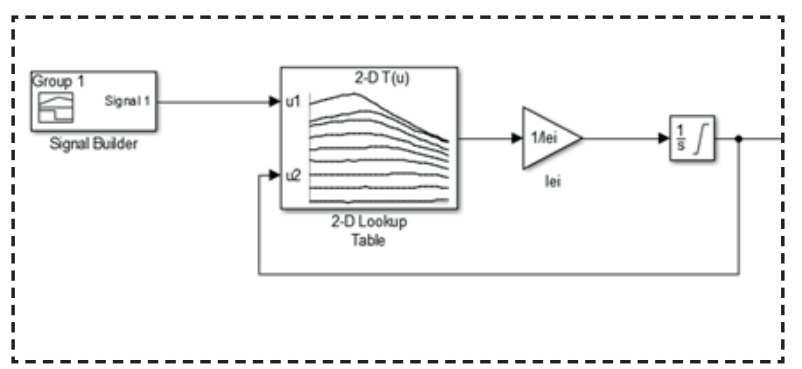

Fig. 11 Engine subsystem

\section{Conclusion}

The advantage of this research is the possible implementation of the autonomous management. The vehicle will know how to accelerate correctly to maximize efficiency and so to achieve the lowest consumption. Laboratory measurements will be used for mathematical computer simulations in SW Simscape, which are oriented for development of new components for transmission of EV.

\section{Acknowledgements}

This paper is supported by the following project: University Science Park of the University of Zilina (ITMS: 26220220184) supported by the Research\&Development Operational Program funded by the European Regional Development Fund, Competence Center for Knowledge Technology Innovation of production systems in industry and services (ITMS: 26220220155) and Project APVV SUSSP- 0014-09. 


\section{References}

[1] BRUMERCIKOVA, E., BUKOVA, B., KRZYWONOS, L.: NFC Technology in Public Transport. Communications - Scientific Letters of the University of Zilina, vol. 18, No. 2, 2016, 20-25. ISSN 1335-4205.

[2] FRANKE, T., NEUMANN, I., BUHLER, F., COCORON, P., KREMS, J. F.: Experiencing Range in an Electric Vehicle -Understanding Psychological Barriers. Applied Psychology: An International Review, 61(3), 2012, 368-391.

[3] FRANKE, T., RAUH, N., KREMS J. F.: Individual Differences in BEV Drivers' Range Stress During First Encounter of a Critical Range Situation. Applied Ergonomics, 2016, 57, 28-35.

[4] SKRUCANY, T., HARANTOVA, V., KENDRA, M., BARTA, D.: Reducing Energy Consumption by Passenger Car with Using of Non-Electrical Hybrid Drive Technology. Advances in Science and Technology Research J., 2017, 166-172.

[5] FATURIK, L., TRSKO, L., HRCEK, S., BOKUVKA, O.: Comparison of Structural Design in High and Ultra-High Cycle Fatigue Regions. Transactions of FAMENA, vol. 38, No. 4, 2014, 1-12. ISSN 1333-1124.

[6] MALIK, L., HRCEK, S.: A General Model of the Transmission Mechanisms Calculation with Speed and Continuously Variable Transmission, Zilina, 2016. ISBN 978-80-554-1239-9.

[7] CACO, M., TRIBULA, R., SCERBA, P., DZUBRIAK, J., KOHAR, R.: Automatic E-frame - Increase Utility Value of the AGV System, ProIN, vol. 17, No. 1, 2016, 34-37. ISSN 1339-2271.

[8] DROZDZIEL, P., KRZYWONOS, L.: The Estimation of the Reliability of the First Daily Diesel Engine Start-up During its Operation in the Vehicle. Eksploatacja i Niezawodnosc - Maintenance and Reliability, 1(41), 2009, 4-10.

[9] Technical Report on EV Laboratory Tests, Ghent University, 2014.

[10] DROZDZIEL, P., KOMSTA, H., KRZYWONOS, L.: Repair Costs and the Intensity of Vehicle Use. Transport Problems, vol. 8, No. 3, 2013, 131-138. 